\title{
Heart-type fatty acid binding protein levels in elderly diabetics without known cardiovascular disease
}

\author{
Selvihan Beysel ${ }^{1,2}$ \\ Muhammed Kizilgul ${ }^{3}$ \\ Mustafa Ozbek ${ }^{4}$ \\ Mustafa Caliskan ${ }^{5}$ \\ Seyfullah Kan ${ }^{6}$ \\ Mahmut Apaydin ${ }^{7}$ \\ Ozgur Ozcelik ${ }^{8}$ \\ Erman Cakal ${ }^{4}$
}

'Department of Endocrinology and Metabolism, Eskisehir State Hospital, Eskisehir, ${ }^{2}$ Department of Medical Biology, Baskent University, Ankara, ${ }^{3}$ Department of Endocrinology and Metabolism, Kilis State Hospital, Kilis, ${ }^{4}$ Department of Endocrinology and Metabolism, Diskapi Yildirim Beyazit Teaching and Research Hospital, Ankara, ${ }^{5}$ Department of Endocrinology and Metabolism, Düzce Ataturk State Hospital, Duzce, ${ }^{6}$ Department of Endocrinology and Metabolism, Denizli State Hospital, Denizlim, ${ }^{7}$ Department of Endocrinology and Metabolism, Yozgat State Hospital, Yozgat, ${ }^{8}$ Department of Endocrinology and Metabolism, Igdir State Hospital, Igdir, Turkey
This article was published in the following Dove Press journal: Clinical Interventions in Aging

\begin{abstract}
Background: Cardiovascular disease (CVD) is reported to be higher in elderly diabetics. Serum heart-type fatty acid binding protein (H-FABP) is a serum marker of myocardial ischemia. We aimed to investigate the association between serum H-FABP level and conventional cardiovascular risk factors, inflammatory markers and subclinical atherosclerosis in elderly diabetics without overt CVD.
\end{abstract}

Patients and methods: A total of 50 elderly diabetic patients without overt CVD and 30 age-, sex- and body mass index (BMI)-matched healthy controls were enrolled. Anthropometric and biochemical parameters, serum H-FABP, high-sensitivity C-reactive protein (hs-CRP), fibrinogen and carotid intima-media thickness (CIMT) were measured. Logistic regression analyses (adjustments for age, sex, hypertension, smoking, diabetes, BMI, blood pressure, lipid, blood glucose, hemoglobin A1c, hs-CRP and fibrinogen) were performed to evaluate the association between H-FABP and cardiovascular risk factors and atherosclerosis indices.

Results: Serum fibrinogen $(421.50 \pm 85.52 \mathrm{mg} / \mathrm{dL}$ vs $319.17 \pm 30.77 \mathrm{mg} / \mathrm{dL}, p=0.023)$, CIMT $(0.70 \pm 0.12 \mathrm{~mm}$ vs $0.59 \pm 0.06 \mathrm{~mm}, p<0.001)$ and hs-CRP $(5.72 \pm 4.50 \mathrm{mg} / \mathrm{dL}$ vs $1.60 \pm 0.72 \mathrm{mg} / \mathrm{dL}$, $p<0.001)$ were significantly higher in diabetic patients than controls. The mean serum H-FABP level did not differ between groups $(1571.79 \pm 604.60 \mathrm{ng} / \mathrm{mL}$ vs $1500.25 \pm 463.35 \mathrm{ng} / \mathrm{mL}$, $p=0.905)$. H-FABP was positively correlated with fibrinogen $\left(r^{2}=0.473, p<0.001\right)$, hs-CRP $\left(r^{2}=0.323, p=0.003\right)$ and CIMT $\left(r^{2}=0.467, p<0.001\right)$. After full adjustments, the serum H-FABP level was independently associated with an increase in the fibrinogen level (odds ratio $[\mathrm{OR}]=4.21,95 \%$ confidence level $[\mathrm{CI}]=1.49-11.90$ ).

Conclusion: Serum H-FABP was similar in the elderly diabetic patients without known CVD when compared with the nondiabetic control group. H-FABP does not possess a high diagnostic value as a cardiovascular marker when used alone; however, it may add supplementary information in patients with a high fibrinogen level.

Keywords: H-FABP, elderly diabetics, cardiovascular risk

\section{Introduction}

Considering the aging population and increased obesity, diabetes is increasingly becoming a serious public health issue especially among the elderly. ${ }^{1,2}$ It has been estimated that one-third of the elderly are diabetic, whereas three-quarters are prediabetic. ${ }^{3}$ Prevalence of cardiovascular disease (CVD), ${ }^{4}$ myocardial infarction (MI) ${ }^{5}$ and CVDrelated mortality ${ }^{6}$ has been reported to be higher in diabetic patients older than 65 years when compared to their nondiabetic peers. Coronary artery disease (CAD) is the leading cause of mortality with the highest prevalence in this group of patients. ${ }^{6,7}$ Silent ischemia is another health issue among elderly diabetic patients. ${ }^{7.8}$ Of all elderly cases
Correspondence: Selvihan Beysel Department of Endocrinology and Metabolism, Eskișehir State Hospital, Yenidoğan Street, 26060 Odunpazarı, Eskișehir, Turkey

Tel +905537465802

Email beyselselvihan@gmail.com $\mathrm{BY}$
hereby accept the Terms. Non-commercial uses of the work are permitted without any further permission from Dove Medical Press Limited, provided the work is properly attributed. For permission

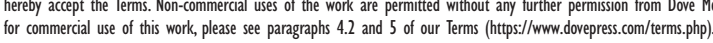


of MI, $12 \%-33 \%$ of males and $26 \%-54 \%$ of females are symptomatic or might not get an accurate diagnosis. ${ }^{9}$ Inflammation plays a major role in atherosclerosis. ${ }^{4,10,11}$ Inflammatory markers such as high-sensitivity C-reactive protein (hs-CRP) and fibrinogen are useful in the determination of CVD risk. ${ }^{4,10-12}$ Subclinical atherosclerosis is characterized by increased carotid intima-media thickness (CIMT) and has been reported to independently predict future cardiovascular events (MI/ischemia and angina). ${ }^{13}$

Heart-type fatty acid binding protein (H-FABP) is a small cytoplasmic protein with a low molecular weight of $15 \mathrm{kDa}$. It is mainly found in the heart but is also present, to a lesser extent, in circulation and extracardiac tissues. ${ }^{14}$ Physiologic function of H-FABP is the transport of hydrophobic longchain fatty acids from cell membrane to intracellular spaces of mitochondrial metabolism, by means of which they join the citric acid cycle. ${ }^{10}$ In the case of acute myocardial infarction (AMI), H-FABP is released in large quantities from myocytes into circulation at an early stage. ${ }^{14}$ It possesses a high diagnostic sensitivity and specificity in AMI and myocardial ischemia and hence could be used as a serum marker of acute coronary syndrome (ACS) and myocardial injury. ${ }^{14,15}$ Several studies were conducted especially among patients without overt CVD but with a high mortality and morbidity risk for cardiovascular events associated with atherosclerosis and inflammatory state. It is demonstrated that H-FABP could be utilized in the determination of subclinical myocardial injury or subclinical atherosclerosis. To date, the role of H-FABP in a number of diseases that pose a risk for cardiovascular events such as metabolic syndrome (MS), ${ }^{17}$ nonalcoholic fatty liver disease (NAFLD), ${ }^{18}$ impaired glucose metabolism, ${ }^{19}$ acromegaly, ${ }^{20}$ hypothyroidism ${ }^{21}$ and insulin-resistant polycystic ovary syndrome (PCOS) ${ }^{22}$ has been investigated by several studies. It is known that diabetic patients have silent subclinical myocardial injury associated with hyperglycemia,

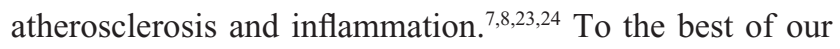
knowledge, there is no study in the literature investigating H-FABP as a marker of subclinical myocardial injury in a population that is at a high risk for CVD, namely, elderly diabetics. In this respect, this is the first study that investigates the association between H-FABP as a marker of subclinical myocardial injury and inflammatory and subclinical atherosclerosis markers ${ }^{16}$ in patients at a high risk for CVD. The purpose of this study is to investigate the association between the serum H-FABP level and conventional cardiovascular risk factors (blood pressure, blood glucose, lipid, smoking and body mass index [BMI]), inflammatory markers (hs-CRP and fibrinogen) and subclinical atherosclerosis (CIMT) in elderly diabetics without overt CVD.

\section{Patients and methods}

A total of 50 elderly (age $\geq 65$ years) diabetic patients without overt CVD and 30 sex- and BMI-matched elderly (age $\geq 65$ years) controls were enrolled in the study. The exclusion criteria included age $<65$ years, poorly controlled diabetes (hemoglobin A1c [HbA1c] $\geq 11 \%$ ), the presence of overt CVD (significant valvular heart disease, dilated cardiomyopathy, heart failure, history of ACS), serum creatinine $\geq 2.5 \mathrm{mg} / \mathrm{dL}$, stroke, severe systemic disease, bedridden status and history of muscle disease. Sex and BMImatched elderly controls were selected without diabetes, CVD or any chronic disease. Each subject signed an informed consent form in accordance with the Declaration of Helsinki, and this study was approved by the local ethical committee of Dişkapi Training and Research Hospital (114/2015).

Baseline demographic data, clinical characteristics, blood sampling and CIMT were obtained in all study subjects. Blood pressure, weight, height and BMI were also measured. Hypertension was defined as resting systolic blood pressure $(\mathrm{SBP})>140 \mathrm{mmHg}$ or diastolic blood pressure (DBP) $>90 \mathrm{mmHg}$ at two different visits or using antihypertensive medication. Dyslipidemia was defined as low-density lipoprotein cholesterol (LDL-C) $>100 \mathrm{mg} / \mathrm{dL}$, high-density lipoprotein cholesterol (HDL-C) $<40 \mathrm{mg} / \mathrm{dL}$ in men and $<50 \mathrm{mg} / \mathrm{dL}$ in women and triglycerides (TGs) $>150 \mathrm{mg} / \mathrm{dL}$ and/or the prescription of anti-lipidemic medications.

Fasting plasma glucose (FPG) and postprandial plasma glucose (PPG), serum total cholesterol, TG, HDL-C, LDL-C and hs-CRP measurements were performed by Beckman Coulter AU5800 (Beckman Coulter Inc., Brea, CA, USA) autoanalyzer. Fibrinogen was measured by ADVIA Centaur XP (Siemens Healthcare Diagnostics Inc., Tarrytown, NY, USA). HbA1c was measured by ion-exchange highperformance liquid chromatography (Tosoh Corporation, Tokyo, Japan). Serum H-FABP was measured by an enzymelinked immunosorbent assay (Hycult Biotech, Uden, the Netherlands). Renal function was evaluated by the estimated glomerular filtration rate (eGFR). eGFR was calculated with the Modification of Diet in Renal Disease equation: e GFR $\left(\mathrm{mL} / \mathrm{min} / 1.73 \mathrm{~m}^{2}\right)=186 \times$ serum creatinine $(\mathrm{mg} / \mathrm{dL})^{-1.154} \times$ age (years) ${ }^{-0.203} \times 0.742$ (if female). CIMT was measured for assessing carotid atherosclerosis. CIMT was defined as the distance between the blood-intima and media-adventitia boundaries on the B-mode imaging high-resolution ultrasound system (Sonoline G4; Siemens, North Middletown, NJ, USA).

\section{Statistical analyses}

Statistical analysis was performed using SPSS 18.0 (SPSS Inc., Chicago, IL, USA) software. Variables are presented as 
mean \pm standard deviation (SD) or median (with interquartile range) values, percentages (\%), odds ratios (ORs) and 95\% confidence intervals (CIs). Normality was tested using the Kolmogorov-Smirnov and Shapiro-Wilk $W$ test. Categorical variables were analyzed using the chi-square test or Fisher's exact test, where appropriate. The Student's $t$-test was used for normally distributed continuous variables. The MannWhitney $U$-test was used for continuous variables that were not normally distributed. Correlations were analyzed using Pearson and Spearman correlation methods. In multiple logistic regression analyses, adjustments for age, sex, hypertension, smoking, diabetes, BMI, SBP, DBP, eGFR, TG, total cholesterol, HDL-C, LDL-C, FPG, PPG, HbA1c, hs-CRP and fibrinogen were carried out. The adjusted variables associated with $\mathrm{H}-\mathrm{FABP}$ ( $\log$ transformed) requiring a probability value of $<0.200$ were entered. Statistical significance was defined as $p<0.05$.

\section{Results}

Clinical and metabolic parameters of subjects are shown in Table 1 . We studied 50 elderly diabetic patients (age

Table I Characteristics of elderly diabetics and elderly nondiabetics

\begin{tabular}{|c|c|c|c|}
\hline Variables & $\begin{array}{l}\text { Elderly } \\
\text { diabetics } \\
(n=50)\end{array}$ & $\begin{array}{l}\text { Elderly } \\
\text { nondiabetics } \\
(n=30)\end{array}$ & $p$-value \\
\hline Male, n (\%) & $23(46.0)$ & $13(43.3)$ & 0.816 \\
\hline Overweight/obesity, n (\%) & $20(40.0)$ & 14 (46.7) & 0.559 \\
\hline Hypertension, n (\%) & $42(84.0)$ & 0 & $<0.001$ \\
\hline Dyslipidemia, n (\%) & $37(74.0)$ & 0 & $<0.001$ \\
\hline Smoking habits, n (\%) & $8(16.0)$ & $3(10.0)$ & $0.45 \mathrm{I}$ \\
\hline Age (years) ${ }^{\mathrm{a}}$ & $70.52 \pm 5.81$ & $70.23 \pm 5.94$ & 0.547 \\
\hline BMI $\left(\mathrm{kg} / \mathrm{m}^{2}\right)^{\mathrm{a}}$ & $29.49 \pm 4.77$ & $29.30 \pm 5.50$ & 0.960 \\
\hline Office SBP $(\mathrm{mmHg})^{\mathrm{a}}$ & $139.40 \pm 17.69$ & $121.33 \pm 7.65$ & $<0.001$ \\
\hline Office DBP $(\mathrm{mmHg})^{\mathrm{a}}$ & $89.40 \pm 14.63$ & $74.50 \pm 6.21$ & $<0.001$ \\
\hline FPG $(m g / d L)^{a}$ & $149.36 \pm 40.74$ & $80.63 \pm 9.96$ & $<0.00$ I \\
\hline PPG $(\mathrm{mg} / \mathrm{dL})^{\mathrm{a}}$ & $243.70 \pm 58.34$ & $108.77 \pm 17.30$ & $<0.001$ \\
\hline 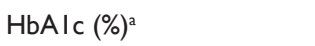 & $8.35 \pm 1.77$ & $5.79 \pm 0.35$ & $<0.001$ \\
\hline Total cholesterol $(\mathrm{mg} / \mathrm{dL})^{\mathrm{a}}$ & $|88.42 \pm 35.8|$ & $|77.03 \pm 20.6|$ & 0.075 \\
\hline TG $(\mathrm{mg} / \mathrm{dL})^{\mathrm{a}}$ & $147.46 \pm 62.62$ & $\mid 40.67 \pm 56.26$ & 0.728 \\
\hline $\mathrm{HDL}-\mathrm{C}(\mathrm{mg} / \mathrm{dL})^{\mathrm{a}}$ & $46.32 \pm 12.93$ & $48.97 \pm 10.30$ & 0.129 \\
\hline LDL-C (mg/dL) ${ }^{\mathrm{a}}$ & $120.72 \pm 32.53$ & $112.30 \pm 18.92$ & 0.147 \\
\hline eGFR $\left(\mathrm{mL} / \mathrm{min} / \mathrm{I} .73 \mathrm{~m}^{2}\right)^{\mathrm{a}}$ & $87.59 \pm 23.00$ & $94.46 \pm 22.59$ & 0.197 \\
\hline hs-CRP (mg/dL) ${ }^{a}$ & $5.72 \pm 4.50$ & $1.60 \pm 0.72$ & $<0.00$ I \\
\hline CIMT score $(\mathrm{mm})^{\mathrm{a}}$ & $0.70 \pm 0.12$ & $0.59 \pm 0.06$ & $<0.001$ \\
\hline $\mathrm{H}-\mathrm{FABP}(\mathrm{ng} / \mathrm{mL})^{\mathrm{a}}$ & I,57I.79 \pm 604.60 & $\mathrm{I}, 500.25 \pm 463.35$ & 0.905 \\
\hline Fibrinogen $(\mathrm{mg} / \mathrm{dL})^{\mathrm{a}}$ & $421.50 \pm 85.52$ & $319.17 \pm 30.77$ & 0.023 \\
\hline
\end{tabular}

Notes: Data are shown as median or percentage. a Data are shown as mean \pm SD. Abbreviations: BMI, body mass index; CIMT, carotid intima-media thickness; DBP, diastolic blood pressure; eGFR, estimated glomerular filtration rate; FPG, fasting plasma glucose; HbAlc, hemoglobin Alc; HDL-C, high-density lipoprotein cholesterol; H-FABP, heart-type fatty acid binding protein; hs-CRP, high sensitivity C-reactive protein; LDL-C, low-density lipoprotein cholesterol; PPG, postprandial plasma glucose; SBP, systolic blood pressure; TG, triglyceride.
Table 2 Correlation of H-FABP with cardiovascular risk parameters

\begin{tabular}{lll}
\hline Variables & $\boldsymbol{r}^{2}$ & $\boldsymbol{p}$-value \\
\hline CIMT & 0.467 & $<0.001$ \\
Fibrinogen & 0.473 & $<0.001$ \\
hs-CRP & 0.323 & 0.003 \\
eGFR & -0.635 & $<0.001$ \\
\hline
\end{tabular}

Abbreviations: CIMT, carotid intima-media thickness; eGFR, estimated glomerular filtration rate; H-FABP, heart-type fatty acid binding protein; hs-CRP, high sensitivity C-reactive protein.

$70.52 \pm 5.81$ years, $46.0 \%$ males, BMI $\left.29.09 \pm 4.77 \mathrm{~kg} / \mathrm{m}^{2}\right)$ and 30 age-, sex- and BMI-matched elderly nondiabetic patients (age $70.23 \pm 5.94$ years, $43.3 \%$ males, BMI $29.30 \pm 5.50 \mathrm{~kg} / \mathrm{m}^{2}$ ). The duration of diabetes was $12.84 \pm 8.05$ years. In all, $88.0 \%$ of diabetic patients were maintained on oral antidiabetic drugs and insulin therapy and $52.0 \%$ of diabetic patients were maintained on only insulin therapy. Blood pressure, FPG, PPG and HbA1c levels were higher in elderly diabetic patients than in elderly nondiabetic patients $(p<0.05)$. Hypertension and dyslipidemia were higher in elderly diabetic patients than in elderly nondiabetic patients $(p<0.001)$. Since $31(62.0 \%)$ diabetic patients were maintained on the antilipidemic agent, mean TG, LDL-C and HDL-C levels were similar between groups. Overweight/obesity and smoking habits were similar between groups $(p>0.05)$. Fibrinogen $(421.50 \pm 85.52 \mathrm{mg} / \mathrm{dL}$ vs $319.17 \pm 30.77 \mathrm{mg} / \mathrm{dL}, p=0.023)$, CIMT $(0.70 \pm 0.12 \mathrm{~mm}$ vs $0.59 \pm 0.06 \mathrm{~mm}, p<0.001)$ and hs-CRP $(5.72 \pm 4.50 \mathrm{mg} / \mathrm{dL}$ vs $1.60 \pm 0.72 \mathrm{mg} / \mathrm{dL}, p<0.001)$ were higher in elderly diabetic patients than in non-elderly diabetic patients. The H-FABP level was not significantly different between elderly diabetic patients and elderly nondiabetic patients $(1,571.79 \pm 604.60 \mathrm{ng} / \mathrm{mL}$ vs $1,500.25 \pm 463.35 \mathrm{ng} / \mathrm{mL}$, $p=0.905)$. H-FABP was not different between elderly nondiabetic patients and elderly diabetic patients after adjusted for sex. H-FABP was positively correlated with fibrinogen $\left(r^{2}=0.473, p<0.001\right)$, hs-CRP $\left(r^{2}=0.323, p=0.003\right)$ and CIMT $\left(r^{2}=0.467, p<0.001\right)$ and negatively correlated with eGFR $\left(r^{2}=-0.635, p<0.001\right.$; Table 2$)$. After full adjustments, elevated log-transformed H-FABP was associated with an increased fibrinogen $(\mathrm{OR}=4.21,95 \% \mathrm{CI}=1.49-11.90$, $p=0.04$ ). The diabetic patients were divided into two groups according to the upper normal level of fibrinogen. H-FABP levels were higher in diabetic patients with the fibrinogen level $>390 \mathrm{mg} / \mathrm{dL}$ than in the diabetic patients with the fibrinogen level $<390 \mathrm{mg} / \mathrm{dL}(1,886.39-1,305.23, p<0.001)$.

\section{Discussion}

In this study, H-FABP was independently associated with fibrinogen in elderly diabetic patients who were at a high 
risk for cardiovascular events. Serum H-FABP, a marker of myocardial ischemia, does not possess a high diagnostic value when used alone in the determination of cardiovascular risk.

In an experimental diabetic model, it was reported that the fatty acid-binding protein content of rat heart was significantly high. It could cause faster consumption of fatty acid in the diabetic heart. ${ }^{15}$ As H-FABP is a small soluble protein, it is released much more rapidly into circulation in response to cardiomyocyte damage than structural proteins such as cardiac troponin. ${ }^{25-27}$ Therefore, it can be used as a sensitive diagnostic marker in the early stage of AMI. ${ }^{25,26,28}$ It can be used to predict long-term mortality in $\mathrm{ACS}^{26}$ and future cardiovascular events in dilated cardiomyopathy. ${ }^{29}$ In addition, it was reported that it could be helpful in the early determination of postoperative myocardial mortality in patients undergoing coronary bypass surgery. ${ }^{30}$ Sari et $\mathrm{al}^{31}$ detected increased perioperative cardiovascular risk by means of early postoperative H-FABP measurements after elective noncardiac surgery in diabetic patients. Several studies found patients without overt CVD but with the cardiovascular risk associated with atherosclerosis and inflammatory state. These studies showed that serum H-FABP measurements might be used for determination of subclinical myocardial injury or subclinical atherosclerosis. It was demonstrated that H-FABP could be helpful in the determination of lowlevel myocardial injury in hypothyroidism ${ }^{21}$ and early stage atherosclerosis in PCOS $^{22}$ and prediabetes. ${ }^{32}$ Patients with the NAFLD were shown to have both subclinical myocardial injury and subclinical atherosclerosis by H-FABP measurements, independent of MS and cardiovascular risk factors. ${ }^{18}$ H-FABP measurements could be determined through myocardial injury in the asymptomatic period in diabetic and even nondiabetic patients with MS. ${ }^{17}$ Thus, elevated H-FABP level suggests having a myocardial injury and/or a high risk for cardiovascular events. ${ }^{31,33}$ In the present study, the H-FABP level did not differ between elderly diabetic patients and elderly nondiabetic patients. Subclinical atherosclerosis (CIMT) and inflammatory markers (fibrinogen and hs-CRP) were higher in elderly diabetic patients. H-FABP positively correlated with fibrinogen, hs-CRP and CIMT in univariate analysis. After full adjustment, H-FABP was independently associated with fibrinogen in elderly diabetic patients who were at a high risk for cardiovascular events $(\mathrm{OR}=4.21,95 \%$ $\mathrm{CI}=1.49-11.90, p=0.04)$.

Age- and sex-adjusted H-FABP was associated with male sex; however, this association disappeared after adjustment for additional cardiovascular risk factors. In addition, the frequency of smoking was higher in patients with high H-FABP levels; however, no association was found between H-FABP and smoking after full adjustment. In agreement with the previous studies, ${ }^{18,21,22,25-31,34}$ the present study demonstrated an association between H-FABP and conventional cardiovascular risk factors, atherosclerosis and inflammatory markers. This partially suggests that H-FABP can be used as a marker of cardiovascular risk, especially in elderly diabetic patients. Both CRP and fibrinogen are acute-phase reactants secreted from hepatocytes after cytokine release has been triggered in the immune system. ${ }^{4,10,11,35}$ Fibrinogen plays a particular role in coagulation. Epidemiological studies showed that elevation in fibrinogen was an independent risk factor for future cardiovascular events. ${ }^{10,11}$ Serum CRP is used as a surrogate marker of CVD. ${ }^{4}$ It was reported that a combination of CRP and fibrinogen was associated with all-cause mortality and CVD-related mortality. ${ }^{36}$ Diabetes and related diseases in urban indigenous population in the Darwin Region study demonstrated that fibrinogen levels increased with age in a population that was at a high risk for CVD and were higher in diabetic patients compared to nondiabetic patients. ${ }^{11}$ In addition, the Strong Heart Study reported that not CRP but fibrinogen was a useful marker in the determination of CVD risk. ${ }^{12}$ The present study showed an association between H-FABP and inflammatory markers (fibrinogen and hs-CRP). This association between H-FABP and fibrinogen did not disappear after full adjustment. As fibrinogen increases with age and diabetes, ${ }^{11,12}$ the combination of fibrinogen and H-FABP might be useful in assessing CVD risk, especially in elderly diabetic patients.

Studies reported an association between CIMT and CRP and/or fibrinogen in elderly patients with subclinical atherosclerosis; ${ }^{37,38}$ this association could not be verified after adjustment for conventional risk factors including adiposity. ${ }^{35-39}$ Studies reported a positive correlation between inflammatory markers and CIMT in elderly; ${ }^{37,38,40}$ however, these studies were performed without adjustment for conventional cardiovascular risk factors, including obesity.

There is no evidence about an association between inflammatory markers and CIMT after adjustment for conventional cardiovascular risk factors including obesity in elderly. The present study demonstrated an association between inflammatory markers and subclinical atherosclerosis. Although the immune system is involved in every stage of atherosclerotic disease, CRP and fibrinogen remain low in the early stage and tend to increase as atherosclerosis progresses. ${ }^{35}$ Therefore, fibrinogen and CRP indicate the extent of the atherosclerotic burden and help predict cardiovascular events. ${ }^{4,10,11,35,36}$ 
This study showed that H-FABP was associated with other factors (hs-CRP and CIMT). It was suggested that these proteins are involved less in early plaque development than fibrinogen. CIMT measurement is a precursor to very serious symptomatic disease ${ }^{37,38,40}$ thus, it was not useful for assessing atherosclerosis in early atherosclerosis. Such factors as muscle wasting and renal insufficiency ${ }^{25}$ should not be overlooked when interpreting H-FABP values, especially in the elderly.

CVD-related mortality and morbidity and the causal relationship could not be determined in this cross-sectional study. The H-FABP level was not different in elderly diabetic patients and elderly nondiabetic patients; this result might have been caused by the limited number of subjects included in the study. In this respect, larger prospective studies are needed that will investigate the potential association between H-FABP and conventional cardiovascular risk factors, inflammatory markers and atherosclerosis. These are limitations of this study.

Limitations of H-FABP that prevent its widespread utilization as a diagnostic marker include the following: it is present in both cardiac and skeletal muscles, thus has a limited cardiospecificity; it has a narrow diagnostic window and it might end in false high values in the case of renal insufficiency. ${ }^{14,16,25-27}$ In the present study, H-FABP, a marker of myocardial ischemia, did not differ between elderly diabetic patients and elderly nondiabetic patients. Nevertheless, univariate analysis showed that H-FABP was associated with the marker of inflammatory (hs-CRP and fibrinogen) and subclinical atherosclerosis (CIMT) in elderly diabetic patients. Multivariate analysis showed that H-FABP was independently associated with fibrinogen in elderly diabetic patients, and H-FABP levels were higher in patients with higher fibrinogen levels. Thus, H-FABP does not possess a high diagnostic value as a cardiovascular marker when used alone; however, it may add supplementary information in patients with a high fibrinogen level.

\section{Disclosure}

The authors report no conflicts of interest in this work.

\section{References}

1. Casagrande SS, Cowie CC, Genuth SM. Self-reported prevalence of diabetes screening in the U.S., 2005-2010. Am J Prev Med. 2014;47(6): 780-787.

2. Boyle JP, Thompson TJ, Gregg EW, Barker LE, Williamson DF. Projection of the year 2050 burden of diabetes in the US adult population: dynamic modeling of incidence, mortality, and prediabetes prevalence. Popul Health Metr. 2010;8:29.

3. Cowie CC, Rust KF, Ford ES, et al. Full accounting of diabetes and pre-diabetes in the U.S. population in 1988-1994 and 2005-2006. Diabetes Care. 2009;32(2):287-294.
4. Emerging Risk Factors Collaboration, Sarwar N, Gao P, et al. Diabetes mellitus, fasting blood glucose concentration, and risk of vascular disease: a collaborative meta-analysis of 102 prospective studies. Lancet. 2010;375(9733):2215-2222.

5. Motta M, Bennati E, Ferlito L, et al. Cardio-cerebrovascular complications in elderly with diabetes. Arch Gerontol Geriatr. 2007;44(3): 261-269.

6. Kronmal RA, Barzilay JI, Smith NL, et al. Mortality in pharmacologically treated older adults with diabetes: the Cardiovascular Health Study, 1989-2001. PLoS Med. 2006;3(10):e400.

7. Corriere M, Rooparinesingh N, Kalyani RR. Epidemiology of diabetes and diabetes complications in the elderly: an emerging public health burden. Curr Diab Rep. 2013;13(6):805-813.

8. Li C-L, Chiu Y-C, Chang H-Y, Hsu K-H, Bai Y-B, Wang H-H. Association of geriatric conditions and cardiovascular diseases with disability in older adults with diabetes: findings from a nationally representative survey. Geriatr Gerontol Int. 2013;13(3):563-570.

9. Leening MJG, Elias-Smale SE, Felix JF, et al. Unrecognised myocardial infarction and long-term risk of heart failure in the elderly: the Rotterdam Study. Heart. 2010;96(18):1458-1462.

10. De Stavola BL, Meade TW. Long-term effects of hemostatic variables on fatal coronary heart disease: 30 -year results from the first prospective Northwick Park Heart Study (NPHS-I). J Thromb Haemost. 2007; 5(3):461-471.

11. Maple-Brown LJ, Cunningham J, Nandi N, Hodge A, O'Dea K. Fibrinogen and associated risk factors in a high-risk population: urban Indigenous Australians, the DRUID Study. Cardiovasc Diabetol. 2010;9:69

12. Kizer JR, Krauser DG, Rodeheffer RJ, et al. Prognostic value of multiple biomarkers in American Indians free of clinically overt cardiovascular disease (from the Strong Heart Study). Am J Cardiol. 2009; 104(2):247-253.

13. Den Ruijter HM, Peters SAE, Anderson TJ, et al. Common carotid intima-media thickness measurements in cardiovascular risk prediction: a meta-analysis. JAMA. 2012;308(8):796-803.

14. Alhadi HA, Fox KA. Do we need additional markers of myocyte necrosis: the potential value of heart fatty-acid-binding protein. QJM. 2004;97(4):187-198.

15. Glatz JF, van der Vusse GJ, Simoons ML, Kragten JA, van DieijenVisser MP, Hermens WT. Fatty acid-binding protein and the early detection of acute myocardial infarction. Clin Chim Acta. 1998;272(1):87-92.

16. Nakata T, Hashimoto A, Hase M, Tsuchihashi K, Shimamoto K. Human heart-type fatty acid-binding protein as an early diagnostic and prognostic marker in acute coronary syndrome. Cardiology. 2003;99(2): 96-104.

17. Akbal E, Özbek M, Güneş F, Akyürek Ö, Üreten K, Delibaşı T. Serum heart type fatty acid binding protein levels in metabolic syndrome. Endocrine. 2009;36(3):433-437.

18. Başar O, Akbal E, Köklü S, et al. Increased H-FABP concentrations in nonalcoholic fatty liver disease. Possible marker for subclinical myocardial damage and subclinical atherosclerosis. Herz. 2013;38(4): $417-422$.

19. Narumi T, Shishido T, Kiribayashi N, et al. Impact of insulin resistance on silent and ongoing myocardial damage in normal subjects: the Takahata study. Exp Diabetes Res. 2012;2012:815098.

20. Ozbek M, Erdogan M, Dogan M, Akbal E, Ozturk MA, Ureten K. Serum heart-type fatty acid binding protein levels in acromegaly patients. J Endocrinol Invest. 2011;34(8):576-579.

21. Gunes F, Asik M, Temiz A, et al. Serum H-FABP levels in patients with hypothyroidism. Wien Klin Wochenschr. 2014;126(21-22):727-733.

22. Cakir E, Ozbek M, Sahin M, et al. Heart type fatty acid binding protein response and subsequent development of atherosclerosis in insulin resistant polycystic ovary syndrome patients. J Ovarian Res. 2012; $5(1): 45$.

23. Rubin J, Matsushita K, Ballantyne CM, Hoogeveen R, Coresh J, Selvin E. Chronic hyperglycemia and subclinical myocardial injury. J Am Coll Cardiol. 2012;59(5):484-489. 
24. Angelico F, del Ben M, Augelletti T, et al. Obstructive sleep apnoea syndrome and the metabolic syndrome in an internal medicine setting. Eur J Intern Med. 2010;21(3):191-195.

25. Schoenenberger AW, Stallone F, Walz B, et al. Incremental value of heart-type fatty acid-binding protein in suspected acute myocardial infarction early after symptom onset. Eur Heart J Acute Cardiovasc Care. 2015;5(2):185-192.

26. Viswanathan K, Kilcullen N, Morrell C, et al. Heart-type fatty acidbinding protein predicts long-term mortality and re-infarction in consecutive patients with suspected acute coronary syndrome who are troponin-negative. J Am Coll Cardiol. 2010;55(23):2590-2598.

27. Haltern G, Peiniger S, Bufe A, Reiss G, Gülker H, Scheffold T. Comparison of usefulness of heart-type fatty acid binding protein versus cardiac troponin $\mathrm{T}$ for diagnosis of acute myocardial infarction. Am J Cardiol. 2010;105(1):1-9.

28. Reiter M, Twerenbold R, Reichlin T, et al. Heart-type fatty acid-binding protein in the early diagnosis of acute myocardial infarction. Heart. 2013;99(10):708-714.

29. Komamura K, Sasaki T, Hanatani A, et al. Heart-type fatty acid binding protein is a novel prognostic marker in patients with non-ischaemic dilated cardiomyopathy. Heart. 2006;92(5):615-618.

30. Muehlschlegel JD, Perry TE, Liu K-Y, et al. Heart-type fatty acid binding protein is an independent predictor of death and ventricular dysfunction after coronary artery bypass graft surgery. Anesth Analg. 2010; 111(5):1101-1109.

31. Sari M, Kilic H, Ariturk OK, Yazihan N, Akdemir R. Diabetic patients have increased perioperative cardiac risk in heart-type fatty acid-binding protein-based assessment. Med Princ Pract. 2015;24(1):53-57.

32. Karbek B, Özbek M, Bozkurt NC, et al. Heart-type fatty acid binding protein (H-FABP): relationship with arterial intima-media thickness and role as diagnostic marker for atherosclerosis in patients with impaired glucose metabolism. Cardiovasc Diabetol. 2011;10:37.
33. O’Donoghue M, de Lemos JA, Morrow DA, et al. Prognostic utility of heart-type fatty acid binding protein in patients with acute coronary syndromes. Circulation. 2006;114:550-557.

34. Dinh W, Nickl W, Füth R, et al. High sensitive troponin T and heart fatty acid binding protein: novel biomarker in heart failure with normal ejection fraction? A cross-sectional study. BMC Cardiovasc Disord. 2011; $11: 41$.

35. Nagasawa S-Y, Ohkubo T, Masaki K, et al; ERA-JUNP Study Group. Associations between inflammatory markers and subclinical atherosclerosis in middle-aged white, Japanese-American and Japanese men: the ERA-JUMP study. J Atheroscler Thromb. 2014;22(6):590-598.

36. Ahmadi-Abhari S, Luben RN, Wareham NJ, Khaw K-T. Seventeen year risk of all-cause and cause-specific mortality associated with $\mathrm{C}$-reactive protein, fibrinogen and leukocyte count in men and women: the EPICNorfolk study. Eur J Epidemiol. 2013;28(7):541-550.

37. Blaha MJ, Rivera JJ, Budoff MJ, et al. Association between obesity, high-sensitivity C-reactive protein $\geq 2 \mathrm{mg} / \mathrm{L}$, and subclinical atherosclerosis: implications of JUPITER from the Multi-Ethnic Study of Atherosclerosis. Arterioscler Thromb Vasc Biol. 2011;31(6):1430-1438.

38. Willeit P, Thompson SG, Agewall S, et al; PROG-IMT study group. Inflammatory markers and extent and progression of early atherosclerosis: Meta-analysis of individual-participant-data from 20 prospective studies of the PROG-IMT collaboration. Eur J Prev Cardiol. 2014; 23(2):194-205.

39. Lorenz MW, Polak JF, Kavousi M, et al; PROG-IMT Study Group. Carotid intima-media thickness progression to predict cardiovascular events in the general population (the PROG-IMT collaborative project): a meta-analysis of individual participant data. Lancet. 2012; 379(9831):2053-2062.

40. Elias-Smale SE, Kavousi M, Verwoert GC, et al. Common carotid intimamedia thickness in cardiovascular risk stratification of older people: the Rotterdam Study. Eur J Prev Cardiol. 2012;19(4):698-705.
Clinical Interventions in Aging

\section{Publish your work in this journal}

Clinical Interventions in Aging is an international, peer-reviewed journal focusing on evidence-based reports on the value or lack thereof of treatments intended to prevent or delay the onset of maladaptive correlates of aging in human beings. This journal is indexed on PubMed Central, MedLine,

\section{Dovepress}

CAS, Scopus and the Elsevier Bibliographic databases. The manuscript management system is completely online and includes a very quick and fair peer-review system, which is all easy to use. Visit http://www.dovepress. com/testimonials.php to read real quotes from published authors. 